\title{
Kernos
}

Revue internationale et pluridisciplinaire de religion grecque antique

2 | 1989

Varia

\section{Revue des actes de colloque}

\section{(2) OpenEdition}

\section{Journals}

Édition électronique

URL : http://journals.openedition.org/kernos/268

DOI : $10.4000 /$ kernos.268

ISSN : 2034-7871

\section{Éditeur}

Centre international d'étude de la religion grecque antique

\section{Édition imprimée}

Date de publication : 1 janvier 1989

Pagination : 272-274

ISSN : 0776-3824

\section{Référence électronique}

"Revue des actes de colloque », Kernos [En ligne], 2 | 1989, mis en ligne le 04 mars 2011, consulté le 22 septembre 2020. URL : http://journals.openedition.org/kernos/268 ; DOI : https://doi.org/10.4000/ kernos.268 


\section{2) Actes de Colloques}

The Function of the Minoan Palaces. Proceedings of the Fourth International Symposium at the Swedish Institute in Athens (10-16 June 1984), éd. par Robin HÄGG et Nanno MARINATOS, Stockholm, Åström, 1987, 344 p. (Instituti Atheniensis Regni Sueciae, Series in $4^{\circ}, 35$ ).

D.J. Ian BEGG, Continuity in the West Wing at Knossos, p. 179-184.

Immo BEYER, Der Palasttempel von Phaistos, p. 213-225.

Christos BOULOTIS, Nochmals zum Prozessionsfresko von Knossos : Palast und Darbringung von Prestige-Objekten, p. 145-156.

Ellen N. DAVIS, The Knossos miniature frescoes and the function of the central courts, p. 157-161.

Geraldine C. GESELL, The Minoan palace and public cult, p. 123-128.

Robin HÄGG, On the reconstruction of the west facade of the palace of Knossos, p. 129-134.

Erik HALlAGER, $A$ "Harvest Festival Room" in the Minoan palaces? An architectural study of the Pillar Crypt Area at Knossos, p. 169177.

Stefan HILler, Palast und Tempel im Alten Orient und im minoischen Kreta, p. 57-64.

M. LINDGREN, The function of the Minoan palaces. Myth and reality, p. 39-42.

Nano MARINATOS, Public festivals in the west courts of the palaces, p. $135-143$.

Wolf-Dietrich NIEMEIER, On the function of the "Throne Room" in the palace at Knossos, p. 163-168.

Ann Charlotte NORDFELDT, Residential quarters and lustral basins, p. 187-194.

Alan PEATFIELD, Palace and Peak. The political and religious relationship between palaces and peak sanctuaries, p. 89-93.

Gösta SÄFLUND, The agoge of the Minoan youth as reflected by palatial iconography, p. 227-233.

IIIe Colloque international des Éudes péloponnésiennes, Kalamata, 8-15 septembre 1985, organisé par la société des Études péloponnésiennes, in Peloponnesiaka, Suppl. 13 (1987-1988).

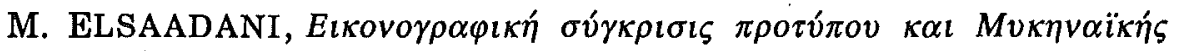

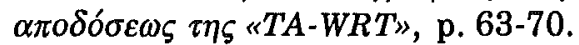

M. JOST, L'iconographie de Pan en Arcadie, p. 219-224.

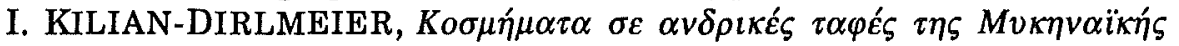

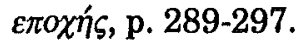


R. LAFFINEUR, Images et symboles dans l'art mycénien, p. 161-174.

V. LAMBRINOUDAKIS, Excavation and Restauration of the Sanctuary of Apollo Maleatas and Asclepios at Epidauros, p. 298-304.

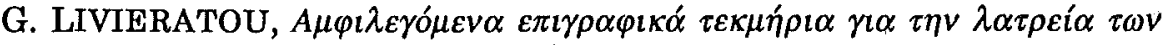

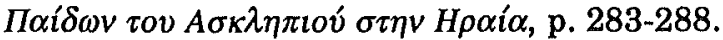

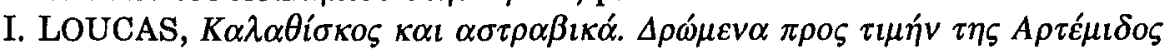

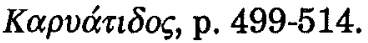

E. LOUCAS, Le nom de la Thea Despoina (Tatien, Ad Graec., 29 - Paus., VIII, 37, 6 et 9), p. 401-419.

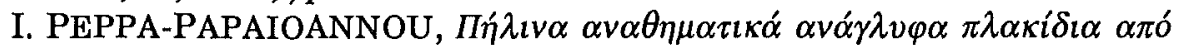

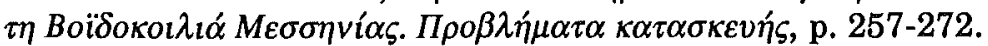

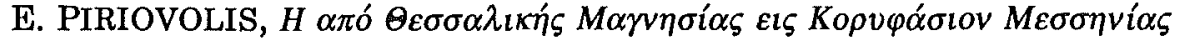

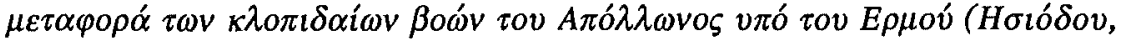
$A \pi \circ \sigma \pi . X X X V I I[165])$, résumé p. 420.

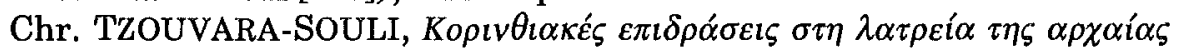
Hлcípov, p. 97-120.

B. WELLS, Apollo at Asine, p. 349-352.

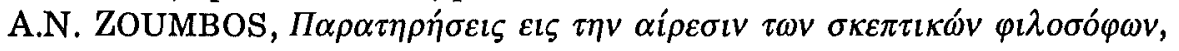
p. 13-14.

Métamorphoses du mythe en Grèce antique, sous la direction de Claude CALAME, Genève, Labor et Fides, 1988, 247 p., 22,4 x 14,8 cm (Religions en perspectives, 4). ISBN : 2-8309-0122-3.

Claude CALAME, Introduction : évanescence du mythe et réalité des formes narratives, p. 7-14.

Claude BÉRARD, La Grèce en barbarie : l'apostrophe et le bon usage des mythes, p. 187-199.

Philippe BORGEAUD, L'écriture d'Attis : le récit dans l'histoire, p. 87103.

Jan BREMMER, La plasticité du mythe: Méléagre dans la poésie homérique, p. 37-56.

Claude CALAME, Mythe, récit épique et histoire : le récit hérodotéen de la fondation de Cyrène, p. 105-125.

Marcel DETIENNE, La double écriture de la mythologie entre le Timée et le Critias, p. 17-33.

Lowell EDMUNDS, La Sphinx thébaine et Pauk Tyaing, l'Gdipe birman, p. 213-227.

Carlos GARCIA GUAL, Élements mythiques et biographie romanesque : la Vie d'Alexandre du Pseudo-Callisthène, p. 127-138.

Fritz GRAF, Ovide, les Métamorphoses et la véracité du mythe, p. 57-70.

Diego LANZA, Redondances de mythes dans la tragédie, p. 141-149.

Nicole LORAUX, Poluneikês epônumos : les noms des fils d'Edipe, entre épopée et tragédie, p. 151-166. 
Gregory NAGY, Mythe et prose en Grèce archaïque : l'aînos, p. 229-242. Ezio PELLIZER, L'enfant et l'oracle : esquisse d'une analyse sémionarrative, p. 71-83.

Wolfgang RÖSLER, Formes narratives d'un mythe dans la poésie épique, la poésie lyrique et les arts plastiques : Ajax de Locres et les Achéens, p. 201-209.

Christiane SOURVINOU-INWOOD, Le mythe dans la tragédie, la tragédie à travers le mythe : Sophocle, Ant. vv. 944-987, p. 167-183.

Peuples et pays mythiques. Actes du Ve Colloque du Centre de Recherches Mythologiques de l'Université de Paris X (Chantilly, 18-20 septembre 1986), réunis par François JOUAN et Bernard DEFORGE, Paris, Les Belles Lettres, 1988, 267 p., 15 x 21,5 cm (Vérité des mythes). Prix : 165 FF.

D. AUGER, Peuples et/ou pays des rêves, p. 91-107.

Bernard DEFORGE, Eschyle et la terre divine, p. 123-132.

Jean HAUDRY, Peuples et pays mythiques de l'Iliade au regard de la "religion cosmique des Indo-Européens, p. 21-30.

A. LALLEMAND, Le parfum comme signe fabuleux dans les pays mythiques, p. 73-90.

Juan Antonio LOPEZ FÉREZ, Les Cyclopes et leur pays dans la littérature grecque, p. 57-71.

H. MATHIEU, Mythe et réalité dans la représentation grecque de l'espace géographique, p. 133-148.

Alain MOREAU, Peuples du bout du monde dans l'œuvre d'Eschyle, p. 109-

J. PEIGNEY, La Phéacie, terre poétique, p. 47-56.

Yvonne VERNIÈRE, Iles mythiques chez Diodore de Sicile, p. 159-167.

Francis VIAN, Le périple océanique des Argonautes dans les Argonautiques orphiques, p. 176-185.

Paul WATHELET, Les Troyens, leurs alliés et les peuples mythiques, p. 31-46. 